AperTO - Archivio Istituzionale Open Access dell'Università di Torino

\title{
Antiphospholipid antibodies negativization: Time for testing for non-criteria aPL?
}

\section{This is the author's manuscript}

Original Citation:

Availability:

This version is available http://hdl.handle.net/2318/1727961

since 2020-02-18T12:03:47Z

Published version:

DOI:10.1177/0961203317711014

Terms of use:

Open Access

Anyone can freely access the full text of works made available as "Open Access". Works made available under a Creative Commons license can be used according to the terms and conditions of said license. Use of all other works requires consent of the right holder (author or publisher) if not exempted from copyright protection by the applicable law. 
Thisis the author'sfinalversion of thecontributionpublishedas:

Lupus. 2017 Nov;26(13):1457-1458. doi: 10.1177/0961203317711014. Epub 2017 May 22.

Antiphospholipid antibodies negativization: time for testing for non-criteria aPL? Radin M, Cecchi I, Pérez-Sánchez C.

The publisher'sversionisavailableat:

https://journals.sagepub.com/doi/abs/10.1177/0961203317711014?rfr dat=cr pub\%3Dpu bmed\&url ver=Z39.88-2003\&rfr id=ori\%3Arid\%3Acrossref.org\&journalCode=lupa

Whenciting, pleaserefer to the publishedversion.

\section{Link to this full text:}

http://hdl.handle.net/2318/1727961 


\section{Antiphospholipid Antibodies Negativization: time for testing for non-criteria aPL?}

Massimo Radin ${ }^{1}$, Irene Cecchi ${ }^{1}$, Carlos Pérez-Sáchez ${ }^{2}$

${ }^{1}$ Center of Research of Immunopathology and Rare Diseases- Coordinating Center of Piemonte and Valle d'Aosta Network for Rare Diseases, Department of Clinical and Biological Sciences,

S. Giovanni BoscoHospital and University of Turin, Turin, Italy

2Maimonides Institute for Research in Biomedicine of Cordoba (IMIBIC)/Reina Sofia

University Hospital/University of Cordoba, Cordoba, Spain.

Running Title: aPL negativization: non-criteria aPL testing?

Key words:

Antiphosphospholipid syndrome - APS - antiphospholipid antibodies- aPL - anticoagulation thrombosis - SLE

\section{Corresponding Author:}

Massimo Radin, MD;

Center of Research of Immunopathology and Rare Diseases- Coordinating Center of Piemonte and Valle d'Aosta Network for Rare Diseases, and SCDU Nephrology and Dialysis, S. Giovanni Bosco Hospital

Piazza del Donatore di Sangue 3, 10154, Turin, Italy.

Email massimo.radin@unito.it Tel +390112402056 Fax +390112402052

This author takes responsibility for all aspects of the reliability and freedom from bias of the data presented and their discussed interpretation 
Dear Editor,

while we read with interest the recent article by Comarmond and Colleagues ${ }^{1}$ about cessation of oral anticoagulants in AntiPhospholipidSyndrome (APS), we do feel there are some points of the study still open for discussion.

Comarmond and Colleagues ${ }^{1}$ describe 10 patients with prolonged disappearance of antiphospholipid antibodies (aPL) that were stopped anticoagulation therapy.After a median duration of follow-up of 19 monthssince the cessation of oral anticoagulant, one out of 10 patients relapsed developing pulmonary embolism.

Recent findings contribute to the hypothesis that persistent negative aPL profile is not an indication to interrupt oral anticoagulant therapy.

Medina and colleagues ${ }^{2}$,investigated aPL negativization in a retrospective study in a large cohort of 70 patients with primary APS. Patients were tested for the presence of aPL, including antiannexin A5 antibodies, and, when found negative, patients were re-tested after 5 years to confirm the disappearance of autoantibodies.Persistent negativization of aPL was detected in $24 / 70$ patients. Since aPL disappearance and after 60months of follow up, 11 out of 24 patients(45.8\%) presented recurrence of thrombosis despite the anticoagulant treatment.

Laboratory criteria for APS include the assays test for the presence of lupus anticoagulant, anticardiolipin antibodies $(\mathrm{aCL})$ and anti- $\beta 2 \mathrm{GPI}$ antibodies (anti- $\beta 2 \mathrm{GPI})^{3}$. However, in patients with persistent disappearance of $\mathrm{aPL}$, a second level screening of non-criteria aPL should be strongly encouraged before stopping the anticoagulant treatment.

For instance, the use of IgA isotypes for both $\mathrm{aCL}$ and anti- $\beta 2 \mathrm{GPI}$ are not a part of the routine diagnostic algorithm ${ }^{4}$. However, some data suggested a role of isolated positivity for IgA antiB2GPI with clinical APS symptoms might help to identify additional patients who are at risk of developing thrombotic events, recommending these tests when other aPL are negative ${ }^{4}$. 
Furthermore, among the so-called extra-criteria aPL tests, anti-phrothrombinmainly antiphosphatidylserine/prothrombin antibodies and anti-ß2GPI glycoprotein-I domain1 antibodies have been proposed to potentially improve the diagnostic accuracy, especially when assessing the risk for both thrombosis and pregnancy morbidities in patients suspected of APS. Other antibody specificities, such as anti-annexin A5 and antivimentinantibodies, might be considered for thrombotic risk assessment only in selected patients, particularly when other aPL tests are negative and in the presence ofclinical APS signs and/or symptoms. Indeed, further investigationsare needed to assess their role in the diagnostic algorithm for APS $^{5}$.Moreover, it would be of great interestto establish anaccurate definition of disappearance of aPL, since it might be important to specify for how long and how many negative tests must be consider to define a patient as negativized.

Persistent aPL disappearance is a hot topic in the field of APS and further prospective studies are needed to assess successful therapeutic strategies. However, a second level screening in patients with aPL negativization is highly suggested before interrupting oral anticoagulation. Besides, when stopping anticoagulation, a physician should consider that aPL are not the only thrombotic risk factor to develop a thrombotic event in a patient. A throughout cardiovascular risk factor evaluation should always be considered and recommended before stopping anticoagulation treatment. 


\section{References}

1. Comarmond C, Jego P, Marie I, et al. Cessation of oral anticoagulants in antiphospholipid syndrome. 2017; $1-6$.

2. Medina G, Briones-García E, Cruz-Domínguez MP, et al. Antiphospholipid antibodies disappearance in primary antiphospholipid syndrome: Thrombosis recurrence. Autoimmun Rev 2017; 16: 352-354.

3. Miyakis S, Lockshin MD, Atsumi T, et al. International consensus statement on an update of the classification criteria for definite antiphospholipid syndrome (APS). J Thromb Haemost 2006; 4: 295306.

4. Bertolaccini ML, Amengual O, Andreoli L, et al. 14th International Congress on Antiphospholipid Antibodies Task Force. Report on antiphospholipid syndrome laboratory diagnostics and trends. Autoimmun Rev 2014; 13: 917-930.

5. Sciascia S, Radin M, Bazzan M, et al. Novel diagnostic and therapeutic frontiers in thrombotic antiphospholipid syndrome. Intern Emerg Med 2017; 12: 1-7. 